Gazi University
Journal of Science
http://dergipark.gov.tr/gujs

\title{
Interpreting Vernacular Settlements Using the Spatial Behavior Concept
}

\author{
Aysegul TANRIVERDI KAYA* \\ Duzce University, Faculty of Art, Design and Architecture, Department of Architecture, Duzce, Turkey \\ Highlights \\ - This paper focuses on vernacular settlements using the spatial behavior concept. \\ - Privacy and territoriality were examined in terms of spatial behavior. \\ - GIS and space syntax methods were used to examine the morphological and syntactic properties.
}

\section{Article Info}

Received: $30 / 04 / 2019$ Accepted: $14 / 11 / 2020$

\section{Keywords}

\section{Privacy}

Spatial behavior

Space syntax

Settlement morphology

Territorial behavior

\begin{abstract}
Villages are traditional settlements accommodating the different cultural infrastructures of the society, and those are where traditional culture can best be observed. The authentic settlement patterns that vary depending on culture are an important input. Houses and their immediate surroundings are the places that most reflect the lifestyle, culture and social understanding of the people who use them and are shaped by their spatial behavior. The social structure of the society can be read by examining the morphology of the settlements through their varying spatial behavior. The hierarchical structure of the space emerges as a result of the spatial behavior types that regulate the relationships of people and their environment, with the phenomena of privacy and territoriality reflected in the physical space. Therefore, syntactic and morphological studies were conducted in five rural settlements composed of different cultural communities in Düzce, with the aim of showing how spatial behavior leads to the morphology of the settlements. Privacy and territoriality were examined in terms of spatial behavior, and GIS and space syntax methods were used to examine the morphological and syntactic properties of the settlements. In conclusion, spatial behaviors were seen as effective in the morphology of the settlements, and the physical structure of the space in all settlement contexts was affected by the social context. According to the five samples, the most important expression of territoriality in traditional settlements is the structure of the street layout. This layout in villages leads to the spatial hierarchy that creates a sense of place.
\end{abstract}

\section{INTRODUCTION}

The level of communication and technological advances reached following the industrial revolution has given our cities a new sense of space. In a globalizing world, expanding knowledge and human mobility affect the relationships between time, space and context. It has been recently acknowledged that the effects of globalization on the built environment have caused a loss of the sense of place [1]. Social and cultural forms are effective in spatial inquiries and need to be considered in the analysis and design of settlements. Houses and their immediate surroundings are the places that most reflect the lifestyle, culture and social understanding of the people who use them and are shaped by their spatial behavior. Rural settlements, where the inhabitants fully reflect their own cultural values and philosophy of existence, are formed by the community via a historical process [2-4].

The definition, formation and importance of housing and its surroundings have been discussed, especially since the destruction of the Pruitt-Igoe apartment blocks. Newman [5] considered the residence and its immediate surroundings as defensible space and Rapoport [4] as non-verbal communication, while Hillier and Hanson [6], Gehl [7] and Can and Heath [8] viewed them as in-between spaces. The problems of urban housing areas, most of which were planned, have been examined and their solutions investigated as a part 
of the city. In addition, traditional settlement models and spatial structure characteristics of rural areas have been investigated in order to contribute to the planning of new settlement areas and to protect the heritage of traditional settlements [9]. This study, on the other hand, deals with the housing and its immediate surroundings in unplanned rural settlements spontaneously formed over time in the context of spatial behavior.

The present study investigated the morphology of rural settlements created by the people according to their own culture. For this purpose, syntactic and morphological studies were conducted in five rural settlements comprised of different cultural communities in Düzce Province. The aim of the research was to show how culture leads to the morphology of a settlement.

First, privacy and territoriality are discussed as concepts of spatial behavior and a brief overview of space syntax is then given. Methods are introduced to define the morphological and syntactic properties of the settlements. After a brief introduction describing the villages in the study area, the findings are discussed, with focus on the interpretation of the morphological features of the villages and their relation with the spatial behavior. Privacy and territoriality were examined in terms of spatial behavior, and GIS and space syntax methods were used to examine the morphological and syntactic properties of the settlements. Both of the methods were used to identify the boundaries created via socio-cultural differences. They were examined in a field survey and from satellite images. The boundaries are constituted according to the culture and value systems and reflect the notion of privacy and the extent of territoriality surrounding the home. The formation of the garden, its usage, and its relationship with the streets was examined and interpreted in terms of privacy and territoriality. The street layout was accepted as the main territorial declaration belonging to the society shaped as a whole.

Very little syntactic research has been carried out on the morphology of villages in Turkey. In general, research has been concentrated on home genotypes and surroundings that are constructed spontaneously in squatter areas [10,11] and historical parts of the cities [12]. The subject of the present study and the villages chosen as the study area are considered to be authentic.

\subsection{Spatial Behavior}

Rural settlements and villages, where human beings fully reflect their cultural values and philosophy of existence, are formed by the flow of the historical process within the community. In these areas, space is produced socially. These settlements, where the structure of the society can also be read, can serve as guides for urban planning. Rapoport [13] emphasized the need to investigate vernacular architecture in the context of human-environment relations. In urban design it is important to ensure an attachment to the site that creates the sense of place [1]. Lefebvre [14] emphasizes that space is not a volume, but rather a social object and that it is produced socially. The open-closed areas that define the morphology of the settlements work as interfaces between physical and social relations and enable us to understand the whole. Data such as settlement texture, relations between the buildings and the streets and integration of the open and closed spaces reflect the social structure of the region [15]. Therefore, the relationship between urban form and social structure constitutes the essence of morphological research $[6,15,16]$. We can define spatial morphology as the relationship of the parts that make up the space and the whole within the settlement scale $[6,15,17,18]$. The physical character of a settlement is also an indication of the social structure of that settlement [4]. Rapaport [4, 13] asserted that culture is an important variable in shaping the environment and is the main determinant of human-environment interaction. Buildings come together to form an open space system in the settlements, and this open space system defined by the buildings determines our spatial behavior. People exhibit spatial-level behavior to regulate their relationships with the environment in which they live $[19,20]$. This spatial behavior has at least two purposes. The first is to convey identity by making arrangements on the physical environment according to beliefs, values and personality traits. The second is to regulate social interaction by controlling areas and objects $[3,4,20]$. These behaviors are important parameters for understanding spatial boundaries. There are four basic spatial boundary-defining factors: 1) administrative rules and practices governing the design and use of space, 2) physical separators that interfere with the flow of people and information, 3) legal regulations controlling internal and external transit, and 4) symbolic boundaries that define the character of public and private spaces [19, 20]. "Boundary" as a word refers to the lower and upper limits of something. A line which marks the limits of 
an area is a dividing line [21]. The physical boundaries in the spatial order correspond to the socio-cultural context. Territoriality is a spatial behavior. It is the space where the boundaries are drawn, making it a unique area of protection used by a person or group. When the housing and the immediate surroundings in the settlement scale are investigated, the hierarchical structure of the phenomenon of spatial behavior reveals the differentiations in the transition from the public realm to the private realm.

Another spatial behavior is privacy. This is defined as the ability of individuals or groups to control their visual, auditory and olfactory interactions with others. Territorial behavior is a mechanism for achieving the desired level of privacy [19, 20, 22, 23] Moreover, a culture or lifestyle that relies heavily upon nonspatial rules and customs to regulate social interactions will depend that much less upon territorial behavior [20].

According to the Rapoport definition $[3,4]$, privacy is the ability to control relationships by making choices to achieve the desired interaction. Territorial behavior becomes part of the control mechanism for ensuring the desired privacy in private and public spaces [19]. Privacy is the total appearance of the mechanisms that regulate and control interaction. Spatial hierarchy is another concept that can be explored to discuss the appearance of behavior in transitional spaces. The definition and degree of privacy that is desired depend on the behavioral patterns in that culture, and on the personality as well as desires of the individual. The use and distance of walls as symbolic or real separators are the mechanisms by which the environmental designer uses certain dimensions to access privacy $[13,24]$. Both privacy and territoriality are mechanisms based on three basic human needs: the need for identity, the need for stimulus and the need for safety [19, 20]. Actually, these behavioral mechanisms constitute boundaries, establish symbols, develop non-verbal attitudes toward the environment and construct a spatial hierarchy within the built environment. The space syntax method is a quantitative description of the built environment. The method is used to explain the relationship between spatial organization and the society [6].

\subsection{Space syntax}

The space syntax analysis method, which is considered a space-reading method, began in the early 1970's as a theoretical study by Hillier and his colleagues in the fields of architecture and urbanism in order to reveal the effects of the spatial appearances of buildings and built environments and their interactions in the social structure $[15,25]$. According to Hillier, this method analyzes the relationship of the spatial components that make up settlements with different morphological features and supports the development of social knowledge related to these fields [26]. Hillier believes that the urban configuration itself is the cause of natural mobility [6]. Hence, the spatial analysis starts with a representation of the pattern of the settlement area, and subsequently, axial maps are generated. These are composed of axial lines combining public spaces for settlements and providing for movement flow and visibility. These maps describe where and how to access the individual in a spatial organization, what kind of relations exist between the spatial composition and the functions that make up that composition and the movement within the space [17]. The purpose of this analysis was to establish the hierarchy of the streets in the settlements connecting to areas ranging from the most frequently accessed to the least-used space. The streets passing through the greatest number of areas are called "integrated" and those passing through the fewest are called "segregated".

The space syntax method can be applied to many different urban scales. There have been many studies on this subject. By questioning the patterns of space and behavior, the relationship between crime and space at the scale of the neighborhood or street can present solutions to problems by increasing the viability and commercial capacity in areas with economic and social collapse [27-29]. The neighborhood street layout and depth of public-private relationships have been examined using this method (space syntax) [29]. The studies of Van Nes have shown that by directing human movements, the street layout-road network influences the distribution of commercial areas, the vitality of streets and roads and economic life [30]. In particular, the conclusion was reached that shops are located in areas where spatial integration is the most common [31].

In addition, this method is being used to solve the problems of today's cities by investigating historical cities and considering the relations between the social and spatial dimensions of their public spaces [32]. In particular, the space syntax approach uses three analysis factors (connectivity-integration-depth) to examine the continuity and change of public spaces in the historical process [32]. Connectivity is related to 
space permeability. Permeability increases in parallel with connectivity. The integration reveals the degree of the relationship between the part and the related whole-space system. When the integration is higher, accessible and controllable space is obtained. Depth, which is another concept, describes the topological accessibility of the whole system.

\section{MATERIAL METHOD}

\subsection{Study Area}

The Duzce region encountered intensive migration from the period of the late Ottoman Empire up to the 1950s. Therefore, it is home to different socio-cultural groups of immigrants and has been likened to "Noah's ark" [33, 34]. Due to their multicultural structure, five Düzce villages were chosen to comprise the study area and the relationship between culture and space was investigated in the context of the spatial behavior in these villages. Villages were selected in two different locations for the study are shown in Figure 1. First, three villages located on the Akçakoca highway were selected as they are far away from the pressure of urbanization. Second, two villages located on the Düzce plain were selected as they are close to the provincial city center of Düzce. After the 1999 earthquakes, Düzce was designated as a separate province, and was then faced with a rapid rebuilding process. The city of Düzce had spread to the plain and was threatening the rural settlements. The Düzce countryside, which contains different cultural environments, was under pressure from intensive urbanization. The villages that had been damaged as a result of the earthquakes and the new construction policies had lost their original texture as the last examples of the interaction between culture and space. For this reason, they were selected as the subject of this research with the aim of examining the local data belonging to the residential environment and acknowledging the messages reflecting the culture of life in these villages. The villages on the Akçakoca highway were chosen because they are more sheltered and original due to their distance from the urban center.

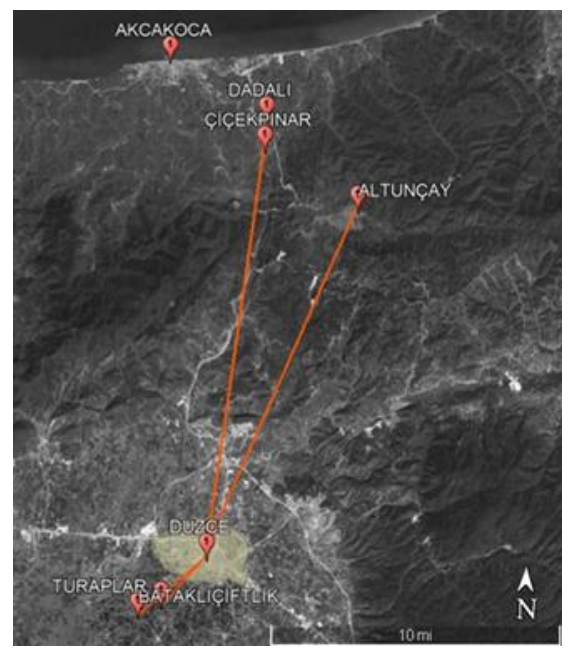

Figure 1. Location of the villages

The village of Altunçay is inhabited by local people called Manav. The village was established on a plain surrounded by mountains covered by dense vegetation and has a population of 494 people. Yerlikaya [35] states that Altunçay and Dadal, which are administratively bound to Akçakoca District, are Turkish villages established in the 1300s. The population of Dadalı is 577. The village of Çicekpınar, mostly consisting of Georgian immigrants, has a population of 214 with a settlement area of $1.15 \mathrm{~km}^{2}$ spread out on mountainous terrain. The village was founded in 1877 by Georgian migrants from Batumi and Acara [35].

Bataklıçiftlik is one of the villages established by Circassian migrants [33] and has a population of 197. The settlement area of $0.21 \mathrm{~km}^{2}$ is located on the Düzce plain. The village of Turaplar has a population of 416 and a settlement area of $0.34 \mathrm{~km}^{2}$. The village is inhabited by local Manav people. However, in the process of conducting the field studies, it was discovered that over time this village had experienced immigration from different cultural groups. 
The main crops grown in all the villages are hazelnuts and corn. In addition, vegetables and small amounts of fruit are grown in the gardens. In interviews with the villagers, they stated that they used to have livestock but that nowadays, no one raises animals. The product range of the villages is the same. Stables are found in most gardens, but nearly all are now used for storage or remain empty. The corn and hazelnuts are kept in garden storehouses. In the garden of almost every house there is an oven for baking bread. All of the five settlements are villages and the village headmen generally stated that their populations were decreasing. Table 1 shows details of the population of the villages.

Table 1. Population of the villages [36].

\begin{tabular}{|c|l|c|c|c|}
\hline \multicolumn{2}{|c|}{ Villages } & Male & Female & Total \\
\hline \multirow{3}{*}{2018} & Düzce (Merkez/Bataklıçiftlik) & 96 & 101 & 197 \\
\cline { 2 - 5 } & Düzce (Merkez/Turaplar) & 207 & 209 & 416 \\
\cline { 2 - 5 } & Düzce (Akçakoca/Altunçay) & 250 & 244 & 494 \\
\cline { 2 - 5 } & Düzce (Akçakoca/Çiçekpınar) & 120 & 125 & 245 \\
\cline { 2 - 5 } & Düzce (Akçakoca/Dadalı) & 294 & 283 & 577 \\
\hline
\end{tabular}

The aim of this research was to investigate how spatial behavior leads to the morphology of a settlement. For this purpose, five villages (Turaplar, Bataklıçiftlik, Dadalı, Altunçay and Çicekpınar) located in the countryside of Düzce Province were chosen because they have preserved their original structures and each of them is composed of a different cultural community. Field studies were conducted in June-August 2018. During this period, a team of three researchers spent a week studying each village. In the villages, photographs were taken and surveys and interviews were conducted with the inhabitants of the village. The methodology of the study mainly involved determining the morphological features of the village settlement area and investigating the social structure by means of the space syntax method. The plans of the settlement areas of the villages were obtained by digitizing satellite images of the villages using ArcGIS 10.6 software. Morphological analyses of the villages were performed and the syntactic properties of the spaces were investigated by using depthmap software. Connectivity and integration values of the settlements were obtained and the intelligibility characteristics of the settlement areas were interpreted by correlating these values. These data, obtained as a result of the morphological examination and syntactic investigation of the settlements through spatial behavior and the concepts of territoriality and privacy, were discussed and the traces of cultural differences of the villages were interpreted.

\subsection{Morphological Analysis}

Rectified satellite images of the five villages selected for the study were digitized using ArcGIS 10.3 software. Settlement plans of the villages were created to scale and coordinated with the maps. Street layout, spatial order and figure-ground maps were obtained using the layout plans. In this study, a morphological framework was used in the spatial and syntactic analyses of the villages. Figure 2 shows the frame of methodology proposed for this research. 


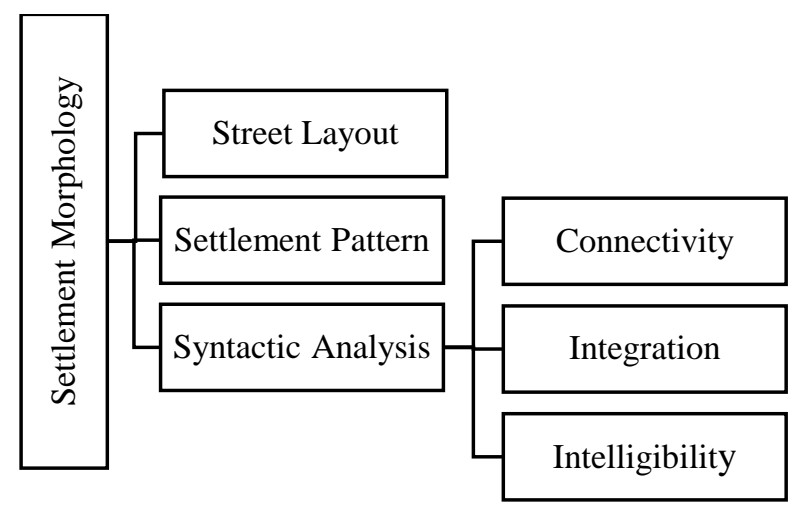

Figure 2. Morphological framework used in the spatial and syntactic analysis of the villages

Privacy is seen as a higher concept in the provision of control over the environment and behavioral mechanisms [19]. In the hierarchy between the private and the public realms, control mechanisms are used to achieve the desired privacy. In this study, spatial behavior is discussed within the context of territoriality and privacy. These concepts were examined in the village settlements and their surroundings, which were considered as comprising the cultural environment. For this purpose, the relationship between housing and public space was examined [3]. Therefore, the roads in the villages were classified according to their intensity of use and Figure 3 shows the street layout and settlement pattern hierarchy depending on territoriality. The road which comes from Düzce is referred to as the main road and is specified as Rank I. Rank II is the main road of the village, which is separated as a branch from Rank I and bears the main vehicle traffic of the village. Rank III roads are the narrow streets, mostly used only by pedestrians, and Rank IV streets are the cul de sacs. The positions of the houses in a parcel were classified according to their proximity to the road. Based on the parcel, the spatial order of a house was classified according to the main façade of the building and its entrance. The relationship of the house with the street was ranked from private to public (Figure 3).
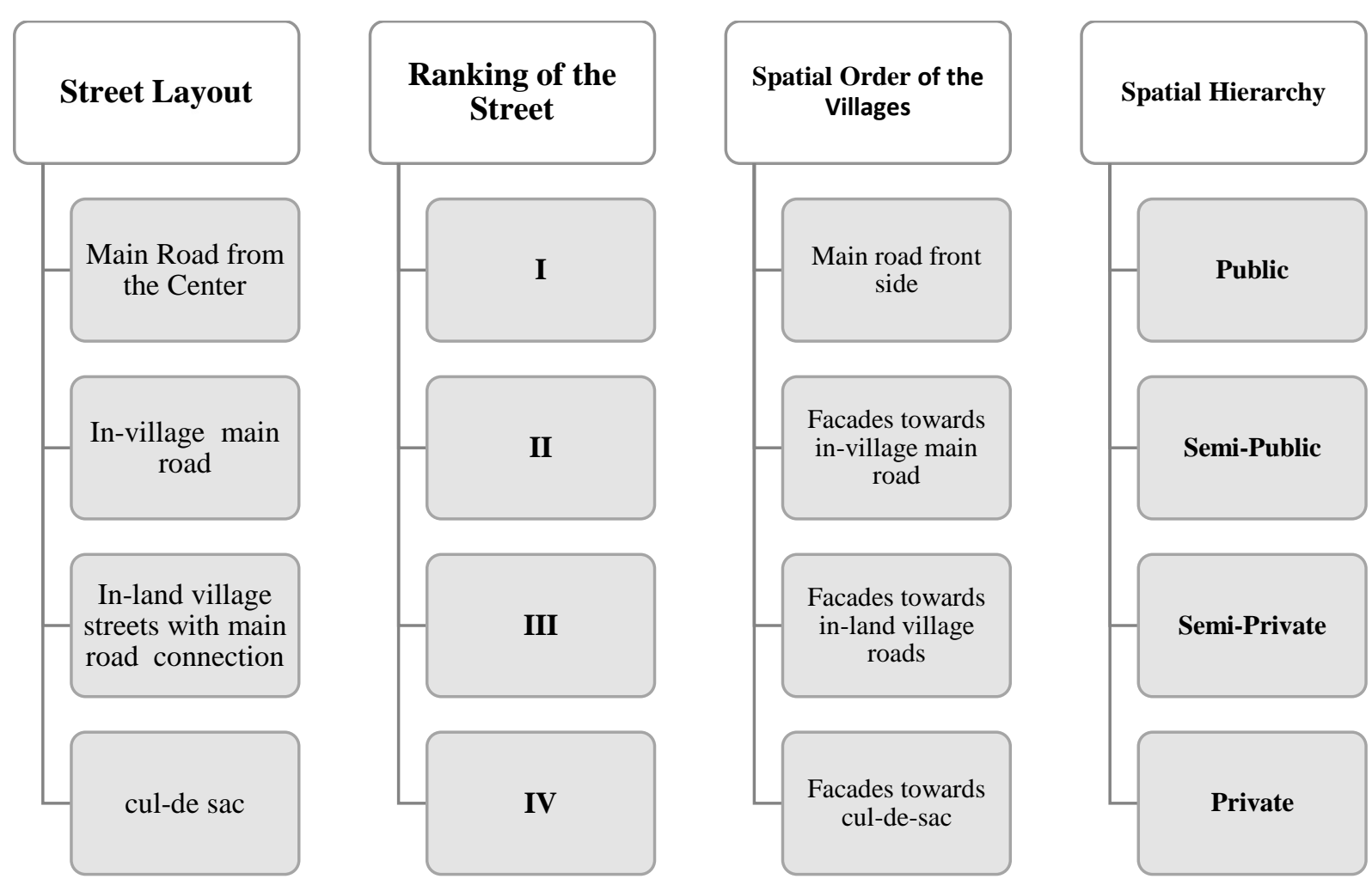

Figure 3. Street layout and settlement pattern hierarchy depending on territoriality 


\subsection{Syntactic Analysis}

In the five villages that constituted the study area, the aim was to read territoriality and privacy through the values of the four syntactic parameters of integration, connectivity, depth and intelligibility. These values were used to interpret the degree to which the settlement was social or conservative and the degree to which the physical structure of the village was permeable and allowed socialization. Axial maps in DXF format were obtained from settlement maps of the villages and integration, correlation and depth analyses of the villages were made using depthmap software. Connectivity provides information on the accessibility of villages. It shows how many paths are directly linked to a system. A higher connectivity means higher accessibility, shows dense relationships and also indicates dense pedestrian movements in the villages [6]. Scatter graphs were produced from the correlation values of the data and intelligibility analyses were performed. Axial maps are linear diagrams that overlap the most distant views with movements passing through the public space in the settlement. In this system, during the movement, if one is deeper or shallower than the other, this indicates that there is more movement or less movement in that area [15]. This depth gives the integration value, which is the most important configuration parameter for the whole. The places that are most intensely passed through are called integrated, while those less frequently passed through are called segregated. Integration and intelligibility are two basic concepts that enable the interpretation of the relationship between the formal characteristics of a field and its socio-cultural characteristics. In all graphs, the transition between the red-yellow-blue color tones and the concepts of depth-shallowness were specified. Attractive spaces, meeting places, frequently used and under-used areas were defined by the integration values. In the analysis of the plans, red expresses the areas with the most intense integration, whereas blue is the deepest and indicates that the areas of integration are low. Integration can be calculated globally or locally for different scales. Global measurements can calculate holistic integration, but a local measurement is limited to a specific location, such as a neighborhood. For global measurements, R-N (Radius infinity) expresses the settlement system on a macro scale and emphasizes urban agglomeration. The global integrity value accounts for the way streets are integrated with each other in the system as a whole, depending on the different orientations of the streets or thoroughfares. Less orientation toward the street indicates a higher value of integrity. Moreover, R-3 (Radius 3) allows us to understand the neighborhood system $[6,15,17]$. The open spaces integrated in the settlements are the gathering areas. They are suitable for commercial, cultural or social activities due to the slowing or stopping of pedestrian movement in these areas $[6,15,17]$.

The formal perception of space can be explained by the correlation between the parameters. The intelligibility of a space is linked to the amount of integration and connection of the system. The manner in which spatial formation appears from parts of the system and its place in the whole system can be measured by analysis of the whole-part relationship $[6,15]$. We cannot see or experience all of the urban area at once; however, we can understand the whole urban system by studying it piece by piece. This is related to how much of the whole-part relationship of the city is perceptible. Intelligibility "...has something to do with the way in which a picture of the whole urban system can be built up from its parts, and more specifically, from moving around from one part to another" [15]. By using these concepts, this study developed a sociocultural interpretation of the spontaneous built environment in the villages.

\section{RESULTS}

\subsection{Village Street Layouts}

The street network, as the basic circulatory system, constitutes the basic skeleton of a settlement that supports the flow of behavior and information. In the study, the streets were defined as borders and as a projection of the territoriality within the space. Site surveys were made and the street layouts were classified using settlement maps obtained via GIS software. The roads that provide access to the villages from the district center were considered as the main roads and a street ranking order was formed in the village street layout, from the main streets to the cul-de-sacs. Hierarchy of streets and spatial order of houses according to the streets are shown in Table 2. 
The Çiçekpınar and Dadalı villages of Akçakoca District are located on hilly terrain. The village of Altunçay is situated on relatively flat land. All three villages are reached by village roads that proceed from the Düzce - Akçakoca highway. In the villages of Altuncay (Figure 4) and Dadalı (Figure 5) the streets separating the small parcels are covered with cobblestone and are on a pedestrian scale. The road intersections form small squares that show an organic order harmonious with the topography (Figures 4, 5). In Altuncay, streets and commercial elements are united at the center of the village where the mosque is located (Figure 4). A hierarchical street layout is seen in both village road schemes (Table 2). Table 2 shows the orientation of the houses according to the road ranking in the villages. There are no houses facing the main road in any of the villages. In two villages, all the houses have entrances from the main road (Bataklıçiftlik and Çicekpınar). In the other villages, the houses have entrances from the road on which they are located. The indication mark shows both the entrance to the houses and rank of the roads. In Çicekpınar, a linear order is formed by the road axial line parallel to the stream passing through the middle of the village. The houses and the main road are on different levels (Figure 6). Houses are located higher or lower than the main road; therefore, some of the entrances to the houses are oriented toward the back yard. The main road is covered with asphalt and is constructed to accommodate vehicle traffic.

Bataklıçiftlik is also located on the Düzce plain. The second road (Rank II.) which constitutes the main transportation axial line of Bataklıçiftlik village is connected to the main road coming from the Düzce urban center (Figure 7). The road is paved with asphalt and suitable for vehicle traffic and forms a boundary for the houses located along it.

Table 2. Hierarchy of streets and spatial order of houses according to the streets.

\begin{tabular}{|c|c|c|c|c|c|c|}
\hline \multirow{2}{*}{$\begin{array}{l}\text { Street Hierarchy } \\
\text { Ranking }\end{array}$} & \multicolumn{5}{|c|}{ VILLAGES } & \multirow{2}{*}{$\begin{array}{l}\text { House } \\
\text { entrance/ } \\
\text { location }\end{array}$} \\
\hline & Altuncay & Bataklıçiftlik & Çicekpınar & Dadalı & Turaplar & \\
\hline $\begin{array}{c}\text { Main Road from } \\
\text { the Center } \\
\text { I }\end{array}$ & & & & & & $\begin{array}{l}\text { Main road } \\
\text { front Side }\end{array}$ \\
\hline $\begin{array}{c}\text { In-village main } \\
\text { road } \\
\text { II }\end{array}$ & $\checkmark \quad \checkmark$ & $\checkmark$ & $\checkmark$ & $\checkmark \checkmark$ & $\checkmark$ & $\begin{array}{l}\text { Facades } \\
\text { towards in- } \\
\text { village main } \\
\quad \text { road }\end{array}$ \\
\hline $\begin{array}{l}\text { Inland village } \\
\text { streets with main } \\
\text { road connection } \\
\text { III }\end{array}$ & $\checkmark \quad \checkmark$ & & & $\checkmark \checkmark$ & $\checkmark$ & $\begin{array}{c}\text { Facades } \\
\text { towards in- } \\
\text { land village } \\
\text { streets }\end{array}$ \\
\hline $\begin{array}{l}\text { Cul-de-sac } \\
\text { IV }\end{array}$ & $\checkmark \quad \checkmark$ & & & $\checkmark$ & $\checkmark$ & $\begin{array}{c}\text { Facades } \\
\text { towards cul- } \\
\text { de-sac }\end{array}$ \\
\hline
\end{tabular}

The village of Turaplar is located on the Düzce plain. The main street of the village proceeds from the Düzce highway and passes through the middle of the village (Figure 8). A hierarchal system can be seen in the street layout, with III- and IV-ranked streets proceeding from the main axial line. The main road which passes through the village is paved with asphalt to accommodate vehicle traffic in addition to forming a boundary for the houses located along it. In the village, the main road (II) and III- and IV-ranked streets are on a pedestrian scale. The street reflects the public face of the houses for all residences of the study area, and a clean, attractive façade is considered as a sign of respectability, with this type and level of care especially applied in Bataklıçiftlik. Furthermore, in Çicekpınar and Bataklıçiftlik (Figures 6 and 7) there are fewer people seen on the streets, while the most intensively used outdoor spaces are the private front courtyards that are recognized as being for personal occupancy. They are generally walled and are considered to be an extension of the house. The front courtyards of the houses in Dadalı (Figure 5), Altuncay (Figure 4) and Turaplar (Figure 8) are smaller than in the other villages and generally used for storage of tools or crops. 

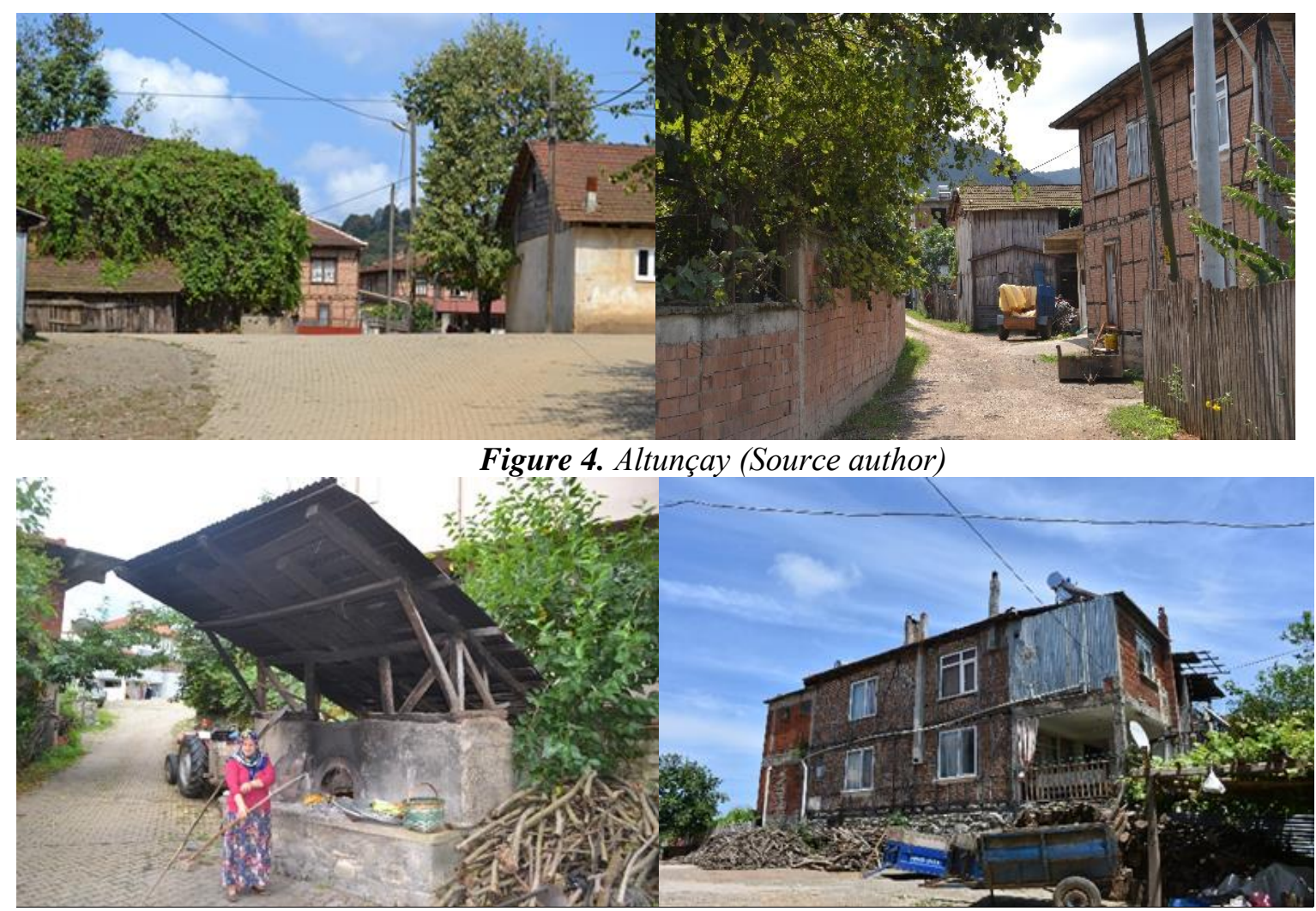

Figure 5. Dadall (Source author)

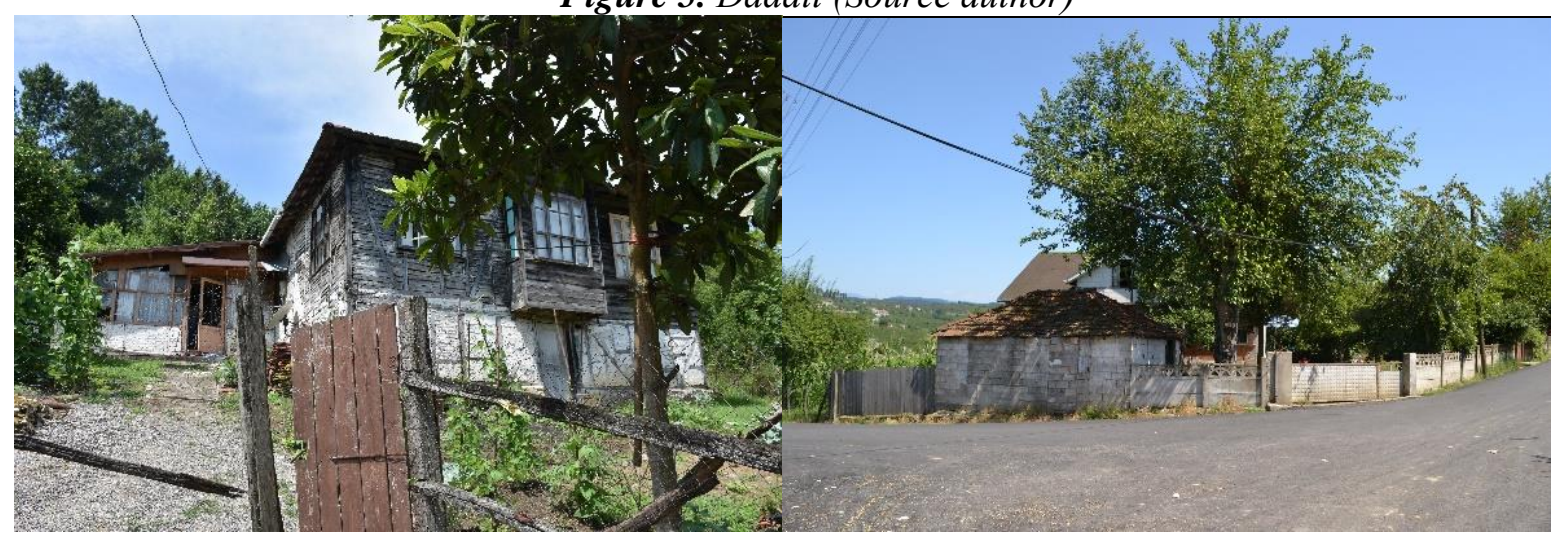

Figure 6. Çicekpınar (Source author)

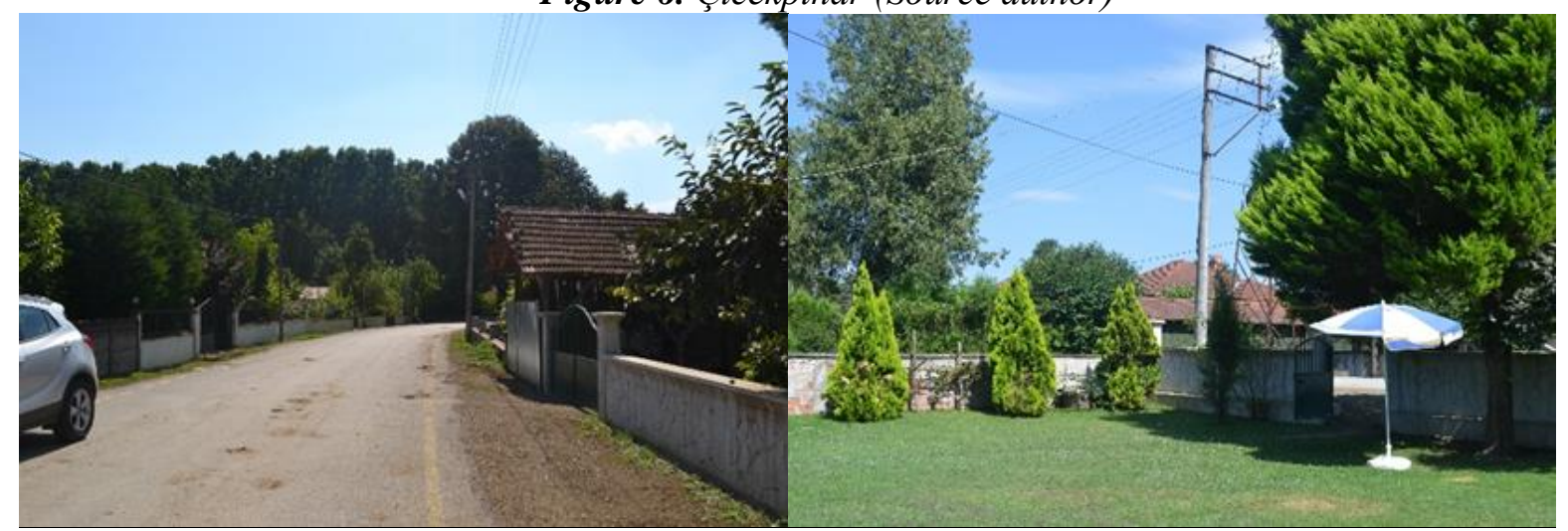

Figure 7. Bataklıçiftlik (Source author)

\subsection{Spatial Order of the Villages}


Distinctively, in four of the five villages where the study was conducted, there are only houses and religious buildings (mosques); however, in the village of Altuncay, there are coffeehouses and markets around the mosque. Settlement layouts of villages are given in Figures 9-13. In the villages surveyed, the borders are mostly formed by roads; however, foliage and plants are used as fences and landscape elements for emphasis and to make the borders visible. In addition to these, the occupancy pattern follows an order consisting of garden + wall + semi private areas + road line. Between the road and the garden border, tractors or trailers and some field equipment were observed. Especially in Dadal1, Altuncay and Turaplar, residents have claim over the sidewalks. Personal objects like gardening materials and pieces of equipment were seen on the sidewalks. In the parcels that make up the rural texture of almost all the villages examined, in addition to the main structure, there are outbuildings or structures around the garden including barns, haystacks, bake ovens, and warehouses for dry storage or others functioning as single-storey service structures. It was determined that these structures are also used as units that regulate borders with neighboring parcels. The gardens with wells, fountains, and ovens provide a connection for the houses with the street, while at the same time limiting the relations with the side parcels. Many of the buildings were on self-built parcels which are limited by the roads opened according to the natural configuration of the land. There are group settlements in Altuncay, Dadalı and Turaplar villages (Figures 9, 10, 12).

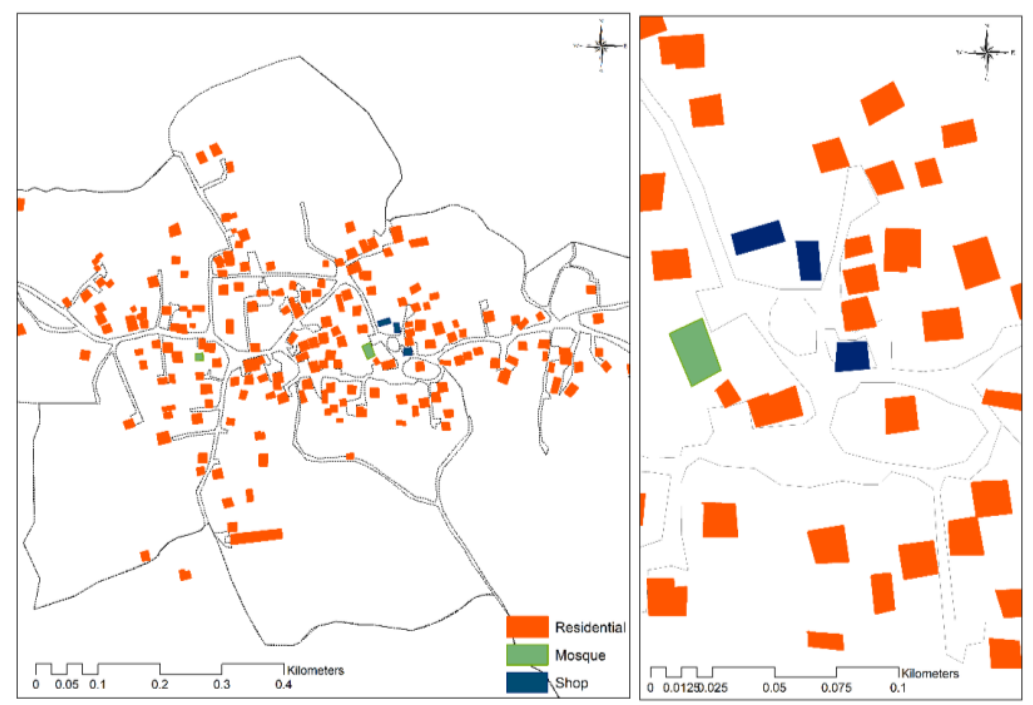

Figure 9. Settlement layout of Altuncay (Generated via Arc GIS 10.3 from satellite archive view, Pleiades OrthoReady pan-sharpened, resolution $70 \mathrm{~cm}, 4$ band, 16 bit, 25.07.2017).

Bataklıçiftlik (Figure 11) lies on a "backbone" formed by the intersection of two roads passing in east-west and north-south directions. It has a linear feature as the settlement is located along the sides of the roads and forms a regular layout pattern. The houses are located behind the main road, but with gardens in front. In general, concrete and/or similar masonry walls have been used or boundaries have been formed by vegetation. There is a public space near the mosque used for religious ceremonies. The houses have been built in groups by taking into account relationships of intimacy and kinship. The houses, which are generally close to each other, are positioned in a way so as not to block the view of the landscape around the fields. In the villages of Altuncay and Dadal1, the smaller plots form a compact structure (Figures 9, 10). In the villages of Dadalı and Altuncay, although the houses are usually situated within gardens, the gardens form small, permeable borders. In the parcels, many houses are located in clusters and there are no clear borders between them. Most of the doors of the dwellings open to the street. There is also a communal bake oven in Dadalı (see Figure 5). 


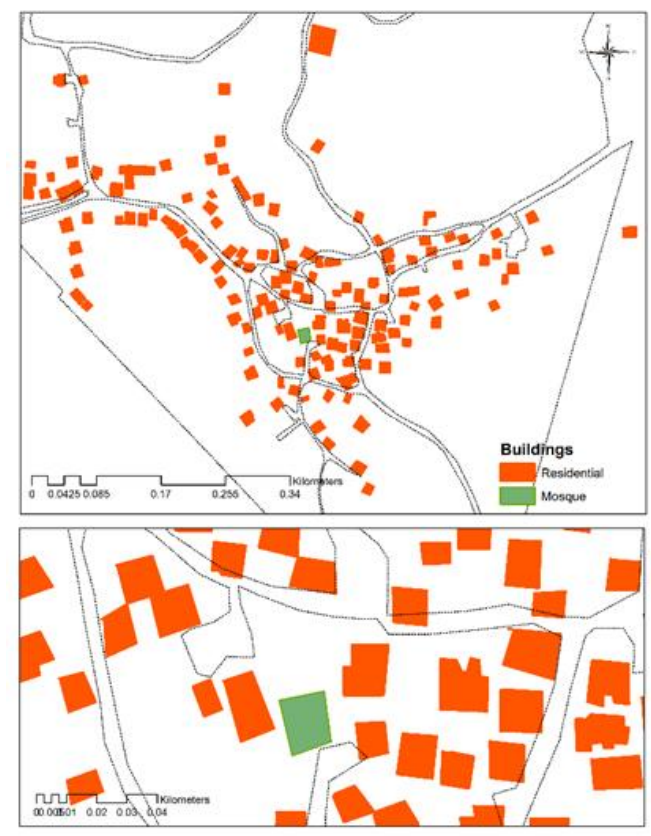

Figure 10. Settlement layout of Dadalı (Generated via Arc GIS 10.3 from satellite view, Pleiades OrthoReady pan-sharpened, resolution $70 \mathrm{~cm}, 4$ band, 16 bit, 25.07.2017)
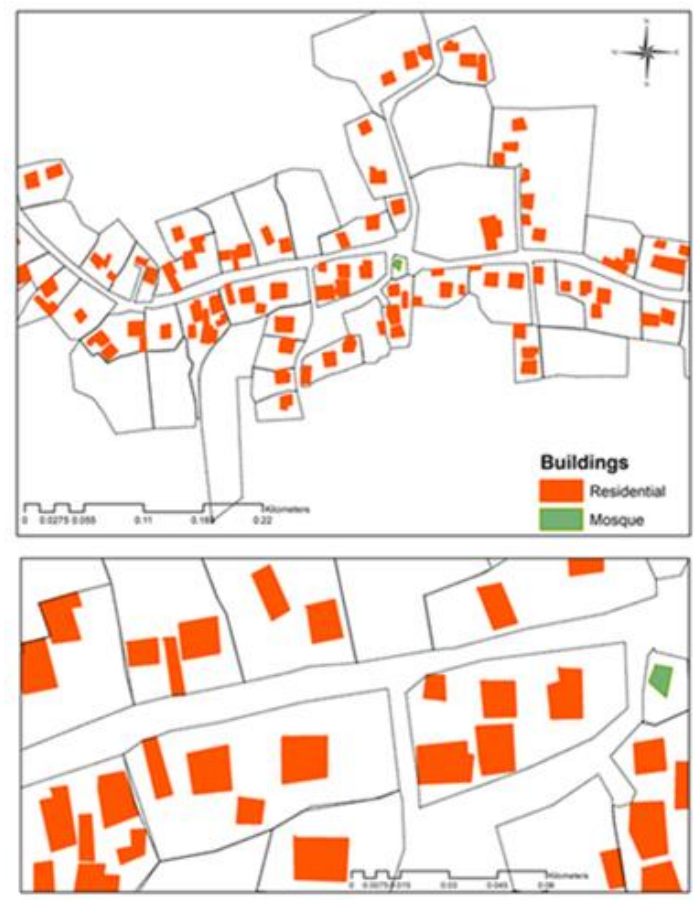

Figure 11. Settlement layout of Bataklıçiftlik(Generated via Arc GIS 10.3 from satellite view, Pleiades OrthoReady pan-sharpened, resolution $70 \mathrm{~cm}, 4$ band, 16 bit, 25.07.2017)

The settlements are centered around the mosque. In contrast, the villages of Batakliçiftlik (Figure 11) and Çicekpınar (Figure 13) show a completely linear layout. Çiçekpınar is located in mountainous, rough terrain. The majority of the village is situated parallel to the stream which passes through the center (Figure 13). The settlement of Çiçekpınar has a scattered layout and this dispersed arrangement provides privacy between the houses.

Turaplar and Bataklıçiftlik are located on the Düzce plain. In Turaplar, the houses are positioned linearly on the sides of the main road passing through the village. Thus, the village is divided into two neighborhoods and shows different structural features. Although the eastern neighborhood is situated in a nearly linear position, there is a central settlement in its western part. There is a main road with dead-end 
streets emerging from this road. The neighborhood located west of the main road exhibits a more centralized, clustered pattern around the mosque.

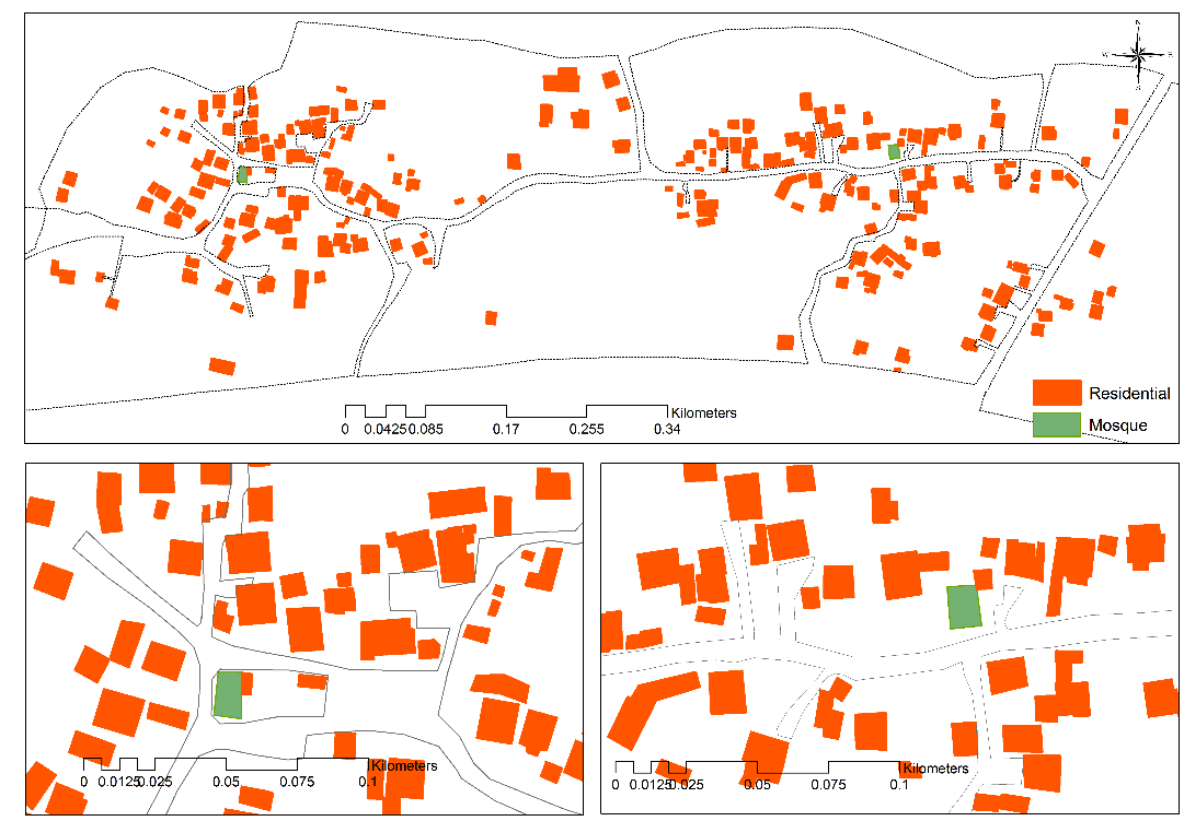

Figure 12. Turaplar (Generated via Arc GIS 10.3 from satellite view. Pleiades OrthoReady pan sharpened, resolution $70 \mathrm{~cm}, 4$ band, 16 bit, 25.07.2017)
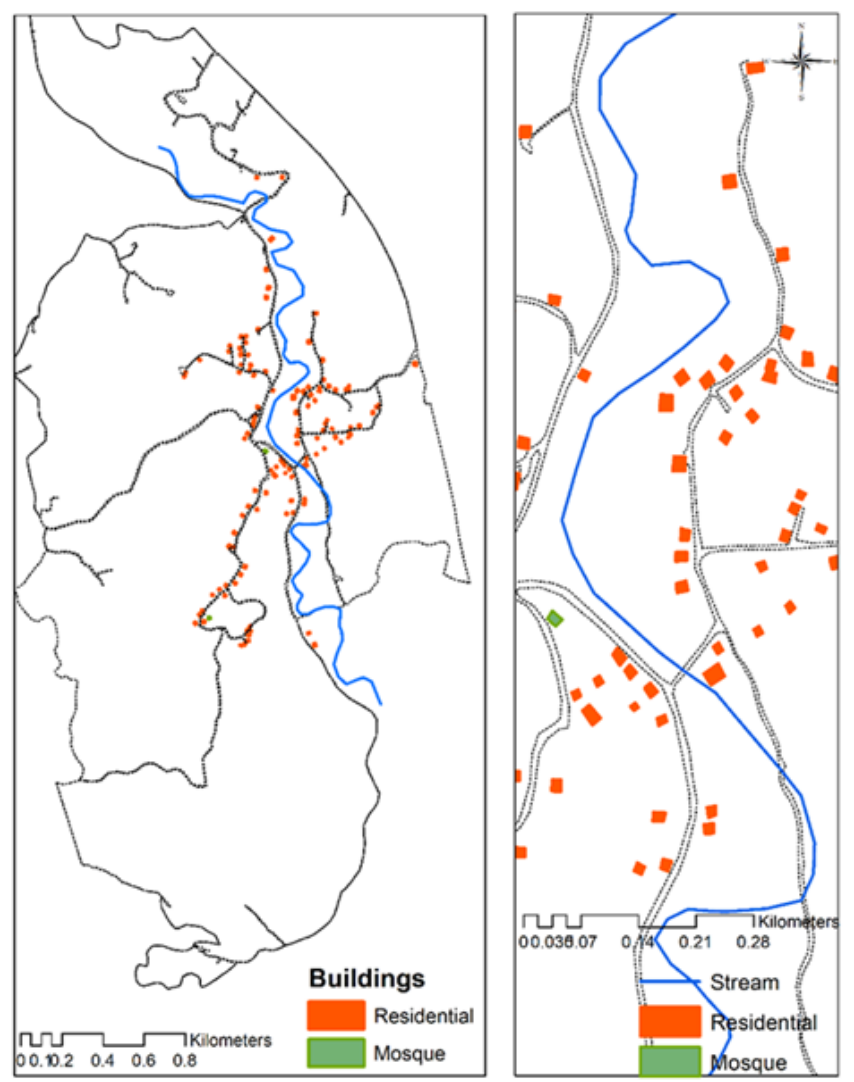

Figure 13. Settlement of Çicekpinar (Generated via Arc GIS 10.3 from satellite view. Pleiades OrthoReady pan-sharpened, resolution $70 \mathrm{~cm}, 4$ band, 16 bit. 25.07.2017)

Figure 14 shows the figure-ground relationships of the villages. According to the figure-ground relations, Altuncay, Dadalı and Turaplar display a compact, dense settlements type, but Çiçekpınar forms an opengrained, scattered settlement type. 


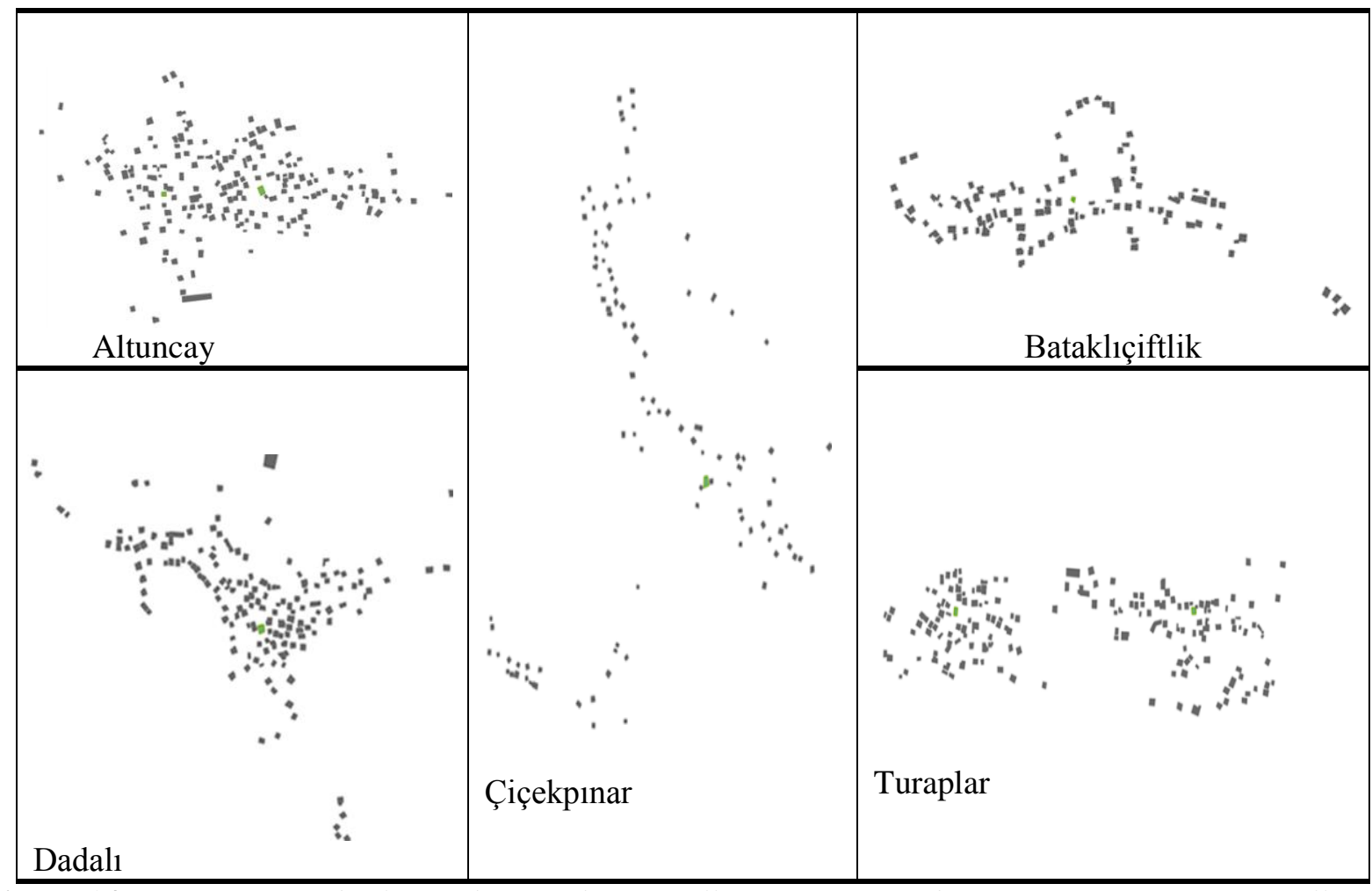

Figure 14. Figure-ground relationships of the five villages (Generated via Arc GIS 10.3 from satellite view. Pleiades OrthoReady pan-sharpened, resolution $70 \mathrm{~cm}, 4$ band, 16 bit, 25.07.2017)

\subsection{Spatial Findings}

When the graphs were evaluated for syntactic analysis, the villages of Altuncay and Batakliçiftlik were seen to have the highest global integration values, respectively (Figures 15 and 16). However, according to the regional scale R-3 value, the village of Batakliçiftlik was identified as the village with the highest integration. Batakliçiftlik is situated on both sides of the main road which divides the village into two rows. The streets, which are not too long, connect the houses to this main road (Figure 16). As seen in the graphs, unlike the other villages, the integrated areas are formed on both sides of the main country road. The road coming from Düzce has a high integration value at the junction of the village mosque and the Turaplar village road. The public gathering area of the mosque and the surrounding village is also found at this intersection. The village of Altuncay has a compact and centralized layout. The village has a macro form scattering out from the center. In the center, there are commercial and social areas such as a mosque, shops, and coffeehouses. There is also a football pitch on the periphery of the main road axial line in the direction of the center. The most intense macro integration values in the charts are seen in this area (Figure 15).

On the local scale, there is integration observed at the intersection points of III- and IV- ranking roads. Moving away from the center, the segregation increases. The short, dead-end streets reached from the center are formed in a hierarchy from public to private.

In Turaplar, global integration values are high on the main road axial line. The integrated areas are located in the more centralized western neighborhood. Similar to Bataklıçiftlik, there are also integrated areas along the same axial line on a macro scale. Batakliçiftlik and Turaplar, which have linear layouts, were found to be higher in intelligibility than the other villages (Figure 16).

Çicekpınar, with lowest intelligibility, has a linear settlement that runs along the river. In addition, the global integration and connectivity values were identified as the lowest for Çiçekpınar, which has a scattered settlement pattern (Figure 17). The village of Dadalı has a compact, center-spread macro form and the integrated areas are located in the center around the mosque (Figure 17). Global integration values are not very high, but higher integrated areas at the local scale are found at the intersections of III- and IVranked roads. 


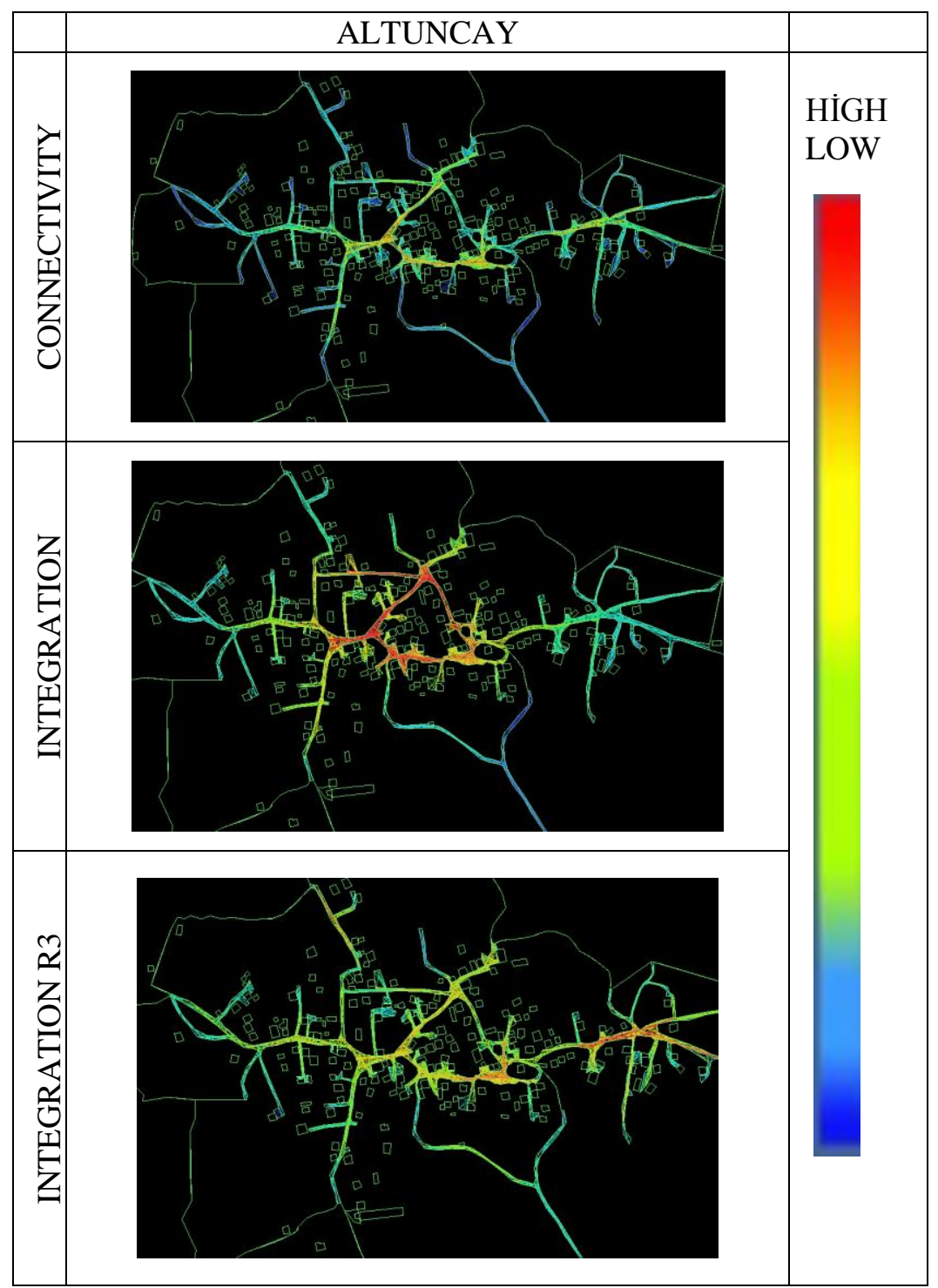

Figure 15. Integration-connectivity maps for Altunçay

Microanalysis (R-3) determines the hierarchy of the local patterns among themselves and identifies areas where the inhabitants are more likely to meet each other [18].

Connectivity, integration and intelligibility values of the villages are shown in Table 3. Generally, the global integration of the villages is low, while the microanalysis values are higher. Macro analysis not only shows the areas that bring the inhabitants of the villages together, but also the areas where the inhabitants and those visiting that village are able to meet. Generally, however, there are more micro integrated areas in the villages than macro integrated areas. Consequently, villagers have a higher chance of meeting together amongst themselves than they do with those coming from outside. This value shows that the villages exhibit certain territoriality towards outsiders. Moreover, this territoriality maintains a certain privacy for the village inhabitants. The village of Bataklıçiftlik is the only village where these two values are high (Table $3)$. 

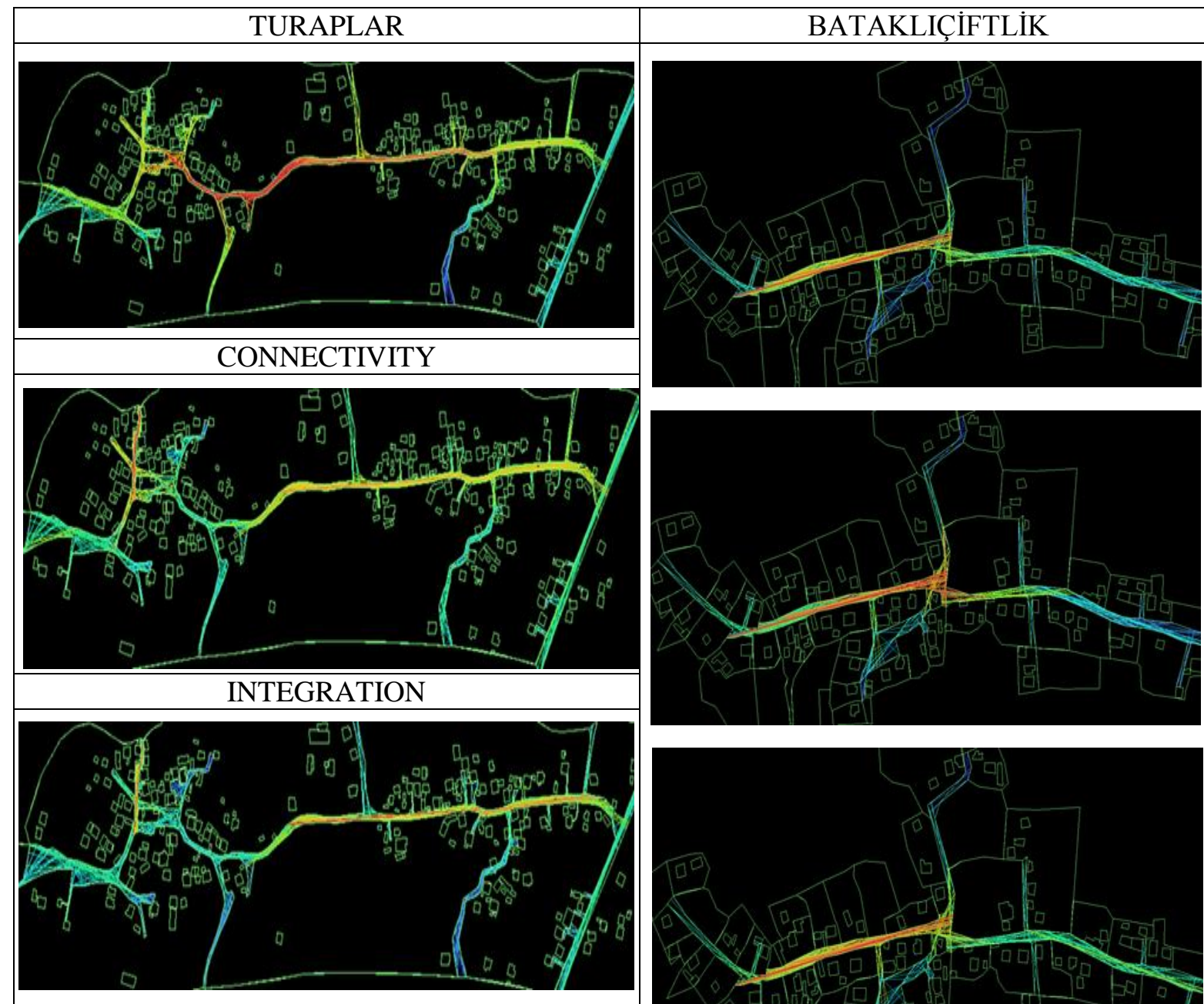

INTEGRATION R-3

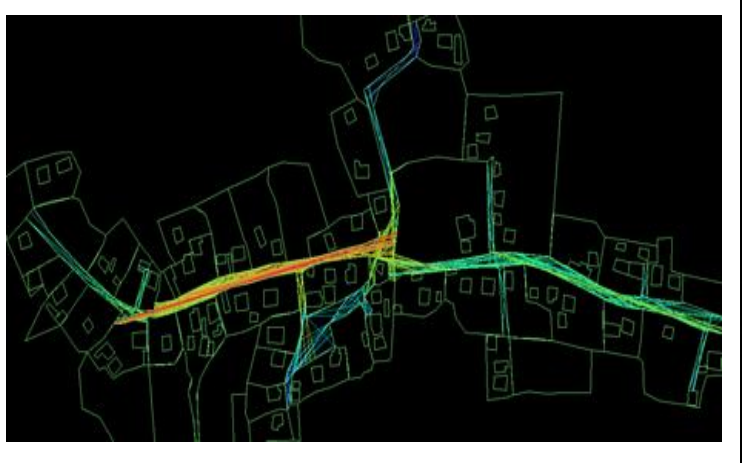

Figure 16. Integration-connectivity maps for Turaplar and Bataklıçiftlik 


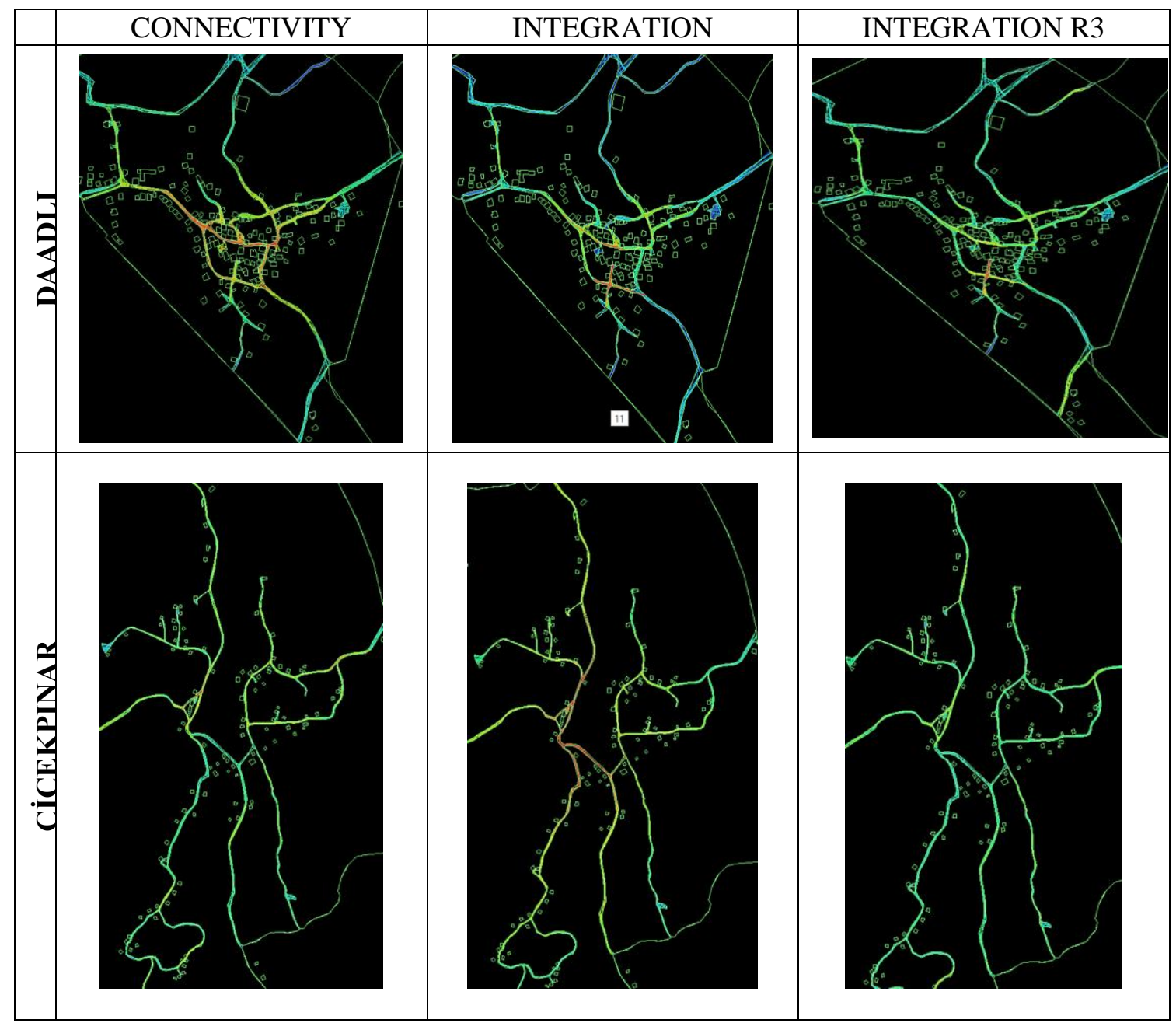

Figure 17. Çicekpınar and Dadalı integration-connectivity maps

Table 3. Connectivity, integration and intelligibility values of the villages

\begin{tabular}{|c|c|c|c|c|c|c|c|}
\hline Villages & & Connectivity & $\begin{array}{c}\text { Integration R- } \\
\mathbf{N}\end{array}$ & $\mathbf{R}-\mathbf{3}$ & $\begin{array}{l}\text { Mean } \\
\text { Depth }\end{array}$ & $\begin{array}{c}\mathbf{R}^{2} \\
\mathbf{R} 3 / \mathbf{R N}\end{array}$ & $\begin{array}{l}\text { Area } \\
\left(\mathbf{K m}^{2}\right)\end{array}$ \\
\hline \multirow{2}{*}{ Altuncay } & Blue & 1 & 0.57 & 1.63 & 4.5 & \multirow{2}{*}{0.199} & \multirow{2}{*}{$0.64 \mathrm{~km}^{2}$} \\
\hline & Red & 12 & 2.24 & 7.09 & 14.24 & & \\
\hline \multirow{2}{*}{ Çiçekpınar } & Blue & 1 & 0.20 & 1.49 & 13.14 & \multirow{2}{*}{0.003} & \multirow{2}{*}{$1.15 \mathrm{~km}^{2}$} \\
\hline & Red & 4 & 0.69 & 7.33 & 43.08 & & \\
\hline \multirow{2}{*}{ Dadalı } & Blue & 1 & 0.54 & 2.03 & 5.09 & \multirow{2}{*}{0.2842} & \multirow{2}{*}{$0.37 \mathrm{~km}^{2}$} \\
\hline & Red & 6 & 1.72 & 5.53 & 14.03 & & \\
\hline \multirow{2}{*}{$\begin{array}{l}\text { Bataklı } \\
\text { Çiftlik }\end{array}$} & Blue & 1 & 1.40 & 1.94 & 1.9 & \multirow{2}{*}{0.388} & \multirow{2}{*}{$0.21 \mathrm{~km}^{2}$} \\
\hline & Red & 8 & 6.17 & 10.73 & 4.43 & & \\
\hline \multirow{2}{*}{ Turaplar } & Blue & 1 & 0.66 & 1.98 & 4.49 & \multirow{2}{*}{0.304} & \multirow{2}{*}{$0.34 \mathrm{~km}^{2}$} \\
\hline & Red & 7 & 2.04 & 6.48 & 11.84 & & \\
\hline
\end{tabular}




\section{DISCUSSION}

In this study, the morphology of the five traditional rural settlements comprised of different cultural communities was examined via the concept of spatial behavior. The space syntax method and morphological analysis were used to examine the villages. The villages were chosen in two different locations, two close to and three away from the provincial city center. Although the physical characteristics of the land in the villages on the Akçakoca highway were almost the same, the settlement forms of the villages were found to be different. As a result of this study conducted in five villages, the location was seen to have no effect on settlements where a certain culture was dominant. The choice of the settlement site and formation of the physical environment were primarily observed in the villages displaying the phenomena of territoriality and the resultant privacy. However, this study also determined that the extent of the desire for privacy differed according to the societies.

When the villages were evaluated according to the results of the morphological and syntactic analyses, territoriality was found to be the highest in Çiçekpınar, which resulted in the highest degree of desired privacy and lesser legibility of the village. Bataklıçiftlik has a geometrical layout, unlike the disorganized patterns of the other villages. The front yards and lawns and their upkeep and design are indications of the taste, status, and lifestyle of the families who live there. Batakliçiftlik is a Circassian village, where it was observed that the desired privacy was obtained by means of the garden layout and foliage. The lowest limit for territoriality and privacy was seen in this village and in addition, the village is equally legible for both insiders and outsiders. On the other hand, in the Turkish villages, two of them located on the Akcakoca highway and one on the Düzce plain, the territoriality is provided by the hierarchy of the streets and the relationship of the houses with the street. In the Turkish villages, the public space and trade area center around the mosque. A hierarchical street structure begins from this public center and separates into the village streets. The house and garden entrances are situated according to this different hierarchy in order to provide the desired privacy.

Today, space organization is not considered on a micro scale in high-density mixed-function projects (residences, malls, offices, etc.) produced on an urban scale. Because the spatial grading from private to public cannot be achieved on an urban scale [27, 29], this approach has a negative impact on the use of urban spaces. Empty streets are dangerous and generally lead to security issues [29]. Spaces created on a small scale provide social control over urban spaces by increasing communication and relationships between individuals or groups $[7,8]$. It was observed in the study conducted in rural settlements that residential areas are safe and livable when socialization and social control is ensured by providing spatial hierarchy in the residences and their immediate surroundings.

\section{CONCLUSION}

Today, whether or not the uniform lifestyle caused by globalization is sufficient for a healthy humanenvironment interaction is the subject of debate. In order to create healthy and happy living spaces, a sense of place must be secured. Furthermore, people need to feel safe and identify with their habitat. The spatial behavior of different cultures is thought to be the most important factor in the construction of an environment. Physical changes at the street and neighborhood level have a great effect on the sense of place. When people identify strongly with a space, they tend to personalize it, and frequently the same objects used as indications of the personality of the occupants also serve as signs of occupancy. It is thought that the most important expression of territoriality in traditional settlements is the structure of the street layout. This layout in villages leads to the spatial hierarchy that creates a sense of place. Territoriality narrows the range of confrontation in various spaces in order to create predictable environments with a consequent sense of order and to achieve security as well as privacy.

If the spatial behavior concept is taken into consideration during the design process for new settlements or temporary settlements for immigrants and others, this approach will make built spaces more livable and will increase the likelihood of appropriation and feelings of attachment for the place by the residents. It is thought that livable spaces can be achieved by considering the needs of the user beyond the physical needs, such as the need for meaning and identity. Thus, participatory planning or user-oriented design processes will help create better living spaces. 
Further research might include an increased number of sample villages in order to arrive at more concrete conclusions.

\section{ACKNOWLEDMENT}

This study was supported by the Scientific Research Project of Düzce University BAP-2017.09.04.608.

\section{CONFLICTS OF INTEREST}

No conflict of interest was declared by the author.

\section{REFERENCES}

[1] Gökçe, D. and Chen, F., "Does typological Process Help to Build a Sense of Place?", Urban Morphology, 20 (1): 66-69, (2016).

[2] Rapoport, A., Human Aspects of Urban Form, Oxford, Pergamon Press, (1977).

[3] Rapoport, A., Human Behaviour and Environment, Volume 4, Environment and Culture, Plenum Press, New York, 9-39(1980).

[4] Rapoport, A., The Meaning of The Built Environment, A Non-verbal Communication Approach, The University of Arizona Press, Arizona, 101-122, (1990).

[5] Newman, O., Defensible Space. Crime prevention through urban design. New York: Macmillan Company, (1972).

[6] Hillier, B. and Hanson, J., The Social Logic of Space, Cambridge University Press, Cambridge, (1984).

[7] Gehl J. Life Between Buildings: Using Public Space, Translated by Jo Koch, Rev.Edition, Island Press, USA, (2011).

[8] Can I.and Heath T. "In-between spaces and social interaction: a morphological analysis of İzmir using space syntax", Journal of Housing and Built Environment, 31:31-49, (2016).

[9] Zhang Y., Baimu S., Tang J., Wang W. "Geometric Spatial structure of traditional Tibetan settlements of Degger county, China: A Case study of four villages", Frontiers of Architectural Research, 7: 304-316, (2018).

[10] Sağlamer G., Dursun P., "Applying morphological analysis to a semi-squatter settlement in İstanbul”, Ekistics, 65(391-392-393): 272-282, (1998).

[11] Dursun, P., Sağlamer G., "Spatial Analysis of Different Home Environments in the City of Trabzon, Turkey", 4th International Space Syntax Symposium, London, (2003).

[12] Yıldırım, G.E., Çağdaş G., "Gaziantep Geleneksel Mimari Dokusunun Sosyo-Kültürel Bağlamda Mekan Dizimsel Analizi”, Gaziantep University Journal of Social Sciences, 17(2): 508-532, (2018).

[13] Rapoport, A., House Form and Culture, Prentice -Hall, Englewood Cliffs, NJ (1969).

[14] Lefebvre, H., The Production of Space, Blackwell, Cambridge, USA, (1991). 
[15] Hillier, B., Space Is the Machine, Cambridge University Press, Cambridge, (1996).

[16] Gökçe, D. and Chen, F., “A Methodological Framework for Defining Typological Process: The Transformation of the Residential Environment in Ankara, Turkey", Journal of Urban Design, 24(3): 469-493, (2019).

[17] Gündoğdu, M., "Mekan Dizimi Analiz Yöntemi ve Araştirma Konulari”, Art-Sanat Dergisi, 2:252-274, (2014).

[18] Gökçe, D. and Chen, F., "Sense of Place in the Changing Process of House Form: Case Studies from Ankara, Turkey", Environment and Planning B: Urban Analytics and City Science, 45(4): 772-796, (2018).

[19] Altman, I. and Chemers, M., "Territorial Behavior", in: Altman, I., Stokols, D. and Wrightsman, L.S. (eds.), Culture and Environment, Cole Publishing Company, California, 120-152, (1984).

[20] Brower, S N., "Territory in Urban Settings", in: Altman, I., Rapoport, A., Wohlwill, J. F. (eds.), Human Behavior and Environment, Springer, New York and Plenum Press, London, 179-207, (1980).

[21] http: //en.oxforddictionaries.com/definition/boundary.

[22] Göregenli, M., Çevre Psikolojisi - İnsan Mekan İlişkileri, İstanbul Bilgi Üniversitesi Yayınları, Istanbul, (2010).

[23] Ünlü, A., Çevresel Tasarımda İlk Kavramlar, İ.T.U Mimarlık Fakültesi Baskı Atölyesi, Istanbul, 28-30, (1988).

[24] Lang, J., "Privacy, Territoriality, and Personal Space-Proxemic Theory", in: Creating Architectural Theory: The Role of The Behavioral Sciences in Environmental Design, Van Nostrand Reinhold, New York, 135-165,(1987).

[25] Karimi K. "A configurational approach to analytical urban design: 'Space syntax' methodology", Urban Design International 17: 297-318, (2012). doi:10.1057/udi.2012.19

[26] Çil, E., "Bir Kent Okuma Aracı Olarak Mekan Dizim Analizinin Kuramsal ve Yöntemsel Tartışması", Megaron, YTÜ Mim. Fak. E-Dergisi, 1(4): 218-233, (2006).

[27] Lopez M and Van Nes, A., "Space and crime in Dutch built environments. Macro and micro spatial conditions for residential burglaries and thefts from cars". In Proceedings Space Syntax. 6th International Symposium, ed. Ayse Sema Kubat, Istanbul Technological University,(2007).

[28] Van Nes A, Rueb L. "Spatial Behaviour in Dutch Dwelling Areas How Housing Layouts Affects the Behaviour of its Users", Proceedings of the 7th International Space Syntax Symposium, Edited by Daniel Koch, Lars Marcus and Jesper Steen, Stockholm: KTH, 123:2,(2009).

[29] Van Nes, A., López, M.J.J., "Micro Scale Spatial Relationships in Urban Studies: The Relationship between Private and Public Space and Its Impact on Street Life", A.S. Kubat, Ö. Ertekin, Y.İ. Güney, E. Eyüboğlu (Eds.), Proceedings, 6th International Space Syntax Symposium, Istanbul Technical University, Cenkler, Istanbul, pp. 023.01-023.12, (2007).

[30] Van Nes, A., "Typology of shopping areas in Amsterdam. In Proceedings Space Syntax", 5th International Symposium. ed. Akkelies van Nes, TU Delft. Amsterdam: Techne Press, (2005). 
[31] Hillier B, Perm A., Hanson J., Grajewski T., Xu J. "Natural movement: or, configuration and attraction in urban pedestrian movement", Environment and Planning B: Planning and Design, (20): 29-66, (1993).

[32] Kamalipour, H, Dorrani A. A, Soltani S. "Understanding Continuity and Change in the Persian Vernacular Settlements: A Comparative Syntactic Analysis of Urban Public Spaces in a Case Study", Current Urban Studies, 1(4): 130-138, (2013).

[33] Özsoy, N., “Çerkez ve Abazaların Düzce'de İskânı ve Kurulan Yeni Yerleşimler”, II. Uluslararası Düzce'de Tarih, Kültür ve Sanat Sempozyumu, 11-12 Aralık 2015, Düzce Belediyesi, İstanbul, 372-389, (2016).

[34] Özlü, Z. “19. Yüzyılda Düzce Kazasına Göçler”, Bilig Türk Dünyası Sosyal Bilimler Dergisi, 61: 201-222, (2012).

[35] Yerlikaya, T.E., "Akçakoca Yöresi”, unpublished thesis, Yakın Doğu Üniversitesi Fen ve Edebiyat Fakültesi, Lefkoşa, (2011).

[36] https://biruni.tuik.gov.tr/medas/?kn=95\&locale=tr(Access date: 12.10.2019). 